\title{
EDITORIAL
}

\section{A New Year!}

\author{
Ra-id Abdulla ${ }^{1}$
}

Published online: 4 February 2021

(c) The Author(s), under exclusive licence to Springer Science+Business Media, LLC part of Springer Nature 2021

\section{A New Year!}

The year 2020 was an exhausting one. We were plagued by fires in Australia and California, global political upheavals with intense manifestations of hatred and xenophobia. And then came a sweeping and devastating pandemic, a replay of the influenza pandemic of the early 1900s.

Whereas nothing magical takes place past midnight December 31 st, there is a psychological sense that perhaps the worst is over, and that one can start looking forward to, God willing, better times. The need to stop and examine past events and plan towards a better future is a helpful exercise and provides hope as one takes the first step towards realizing progress. It was encouraging that even before the year was over, the introduction of several COVID-19 vaccines became a reality and promised a brighter future. The speed with which this was accomplished required resolve, pooling of resources and tapping into scientific ingenuity.

As we start 2021, we are grateful that Pediatric Cardiology, through the support of many bright and dedicated pediatric cardiology physicians, surgeons and researchers across the globe has thrived and continued its progress. We were fortunate to receive an unusual large number of submitted scientific works for publication this past year, more than 1.5 times what we received the previous year. It would have been impossible to assess this large number of submissions had it not been for the tireless efforts of the journal's editors and advisory editorial board members whose skills and dedication allowed the journal to continue serving our community.

The editors of Pediatric Cardiology, like any other journal, are responsible for the review of manuscripts submitted by researchers from all around the world. Unlike many other journals, manuscripts submitted to Pediatric Cardiology are reviewed by physicians, surgeons and scientists in our field who constitute the members of our advisory editorial board.

Ra-id Abdulla

RAbdulla@luriechildrens.org

1 Anne \& Robert H. Lurie Children's Hospital of Chicago, Feinberg School of Medicine, Northwestern University, Chicago, IL, USA
It is, therefore, essential that we continually update the membership of our editorial staff and advisory editorial board members whose only compensation for their immense effort and time is the satisfaction from promoting scientific progress. We are therefore, pleased to announce that Dr. Karim Diab, who for many years participated in many aspects of the journal's operations, will now assume the role of coeditor of Pediatric Cardiology. Dr. Diab's first involvement in Pediatric Cardiology was when he was a fellow in training more than 15 years ago.

It is customary for educators in pediatric cardiology to combine teaching clinical skills with research mentoring. An important aspect of research training is to learn how to critically examine published research, identify where further research is needed, learn how to construct a research project and analyze findings, then finally acquire the know how to compose a manuscript which accurately and succinctly convey the research performed and the results attained. As an educator and editor for most of my career, I found that not only did my role as educator help me in my editorial work, but the reverse was also true; being an editor gave me a valuable insight as an educator. I, therefore, used this dual role as I trained my fellows in pediatric cardiology and engaged many of them in the process of manuscript review to prepare them in their quest to be clinician scientists. Dr. Diab, as a fellow in training, enjoyed examining scientific works to see beyond what they portray on the surface, exposing strengths and weaknesses of studies. More importantly, he quickly learned how a study could work around inevitable limitations and weaknesses and knew how to provide meaningful solutions on how to rectify errors and properly portray conclusions. Learning this process from the early years of training allowed Dr. Diab to be an effective reviewer and later a talented editor.

We hope to continue our efforts this year in providing pediatric cardiologists, congenital heart surgeons and all others concerned with the field of pediatric and congenital heart diseases with original studies which we hope would 
enrich our understanding of these diseases and improve the clinical care we provide our patients. Furthermore, we hope to provide through review articles updated and comprehensive reviews of the state of art in diagnosing and managing our patients.

I am most gratified to be joined this year by Dr. Diab in co-editing Pediatric Cardiology and look forward to handing over the reins to him as I hope, thereafter, to tackle other editorial endeavors.
Hard times certainly intensifies the challenges of our journeys. We pray that these trials leave us with a larger dose of knowledge, wisdom and empathy.

Ra-id Abdulla, MD

\section{Co-Editor-in-Chief}

Publisher's Note Springer Nature remains neutral with regard to jurisdictional claims in published maps and institutional affiliations. 